\title{
APROXIMAÇÃO: DIALOGANDO SOBRE CONTATOS EXTRAMUROS
}

\author{
Fernanda Hermínia Oliveira Souza \\ Universidade do Estado do Rio de Janeiro \\ herminia.fernanda@gmail.com \\ Leidiane Mendonça de Sena \\ Universidade do Estado do Rio de Janeiro \\ leidianesena@yahoo.com.br
}

\author{
Christine Vieira Pereira \\ Universidade do Estado do Rio de Janeiro \\ psichristinevieirapereira@gmail.com \\ Leila Maria Torraca de Brito \\ Universidade do Estado do Rio de Janeiro \\ torraca@uerj.br
}

\begin{abstract}
Resumo
Este artigo visa apresentar atividades desenvolvidas por projeto de extensão universitária que teve como objetivo promover espaço de escuta, conversação e reflexão sobre vínculos afetivos com pessoas cumprindo pena em unidades semiabertas da Secretaria de Administração Penitenciária do Estado do Rio de Janeiro (SEAP). Serão aqui informados e discutidos os resultados obtidos nos cinco encontros efetuados em quatro unidades de regime semiaberto, onde foram realizados grupos com detentos. Observou-se a importância de desenvolver atividades que possibilitem trabalhar a transição do momento vivido dentro do regime prisional para o contexto extramuros, colaborando-se com a reflexão sobre projetos de vida em liberdade.
\end{abstract}

Palavras-chave: Sistema Penitenciário. Regime Semiaberto. Extensão Universitária.

\section{RAPPROCHEMENT: TALKING ABOUT CONTACTS OUTSIDE THE PRISION}

\begin{abstract}
This work aims to present the activities undertaken by university extension project which endorsed a space for listening, conversation and reflection on emotional bonds with prison inmates in semi-open conditions in prison units of the State of Rio de Janeiro (Brazil). It will be informed and discussed the results obtained in five meetings performed in four semi-open conditions units, where groups with the detainees were held. It was observed the need of developing activities that enable prison inmates to work the transition process among life in prison and life outside prison, collaborating with the need of develop life projects when they were to be released. Keywords: Prison System. Semi-open Conditions. University Extension Project.
\end{abstract}

\section{APROXIMACIÓN: DIÁLOGO SOBRE CONTACTOS FUERA DE LOS MUROS}

\section{Resumen}

Este artículo tiene como objetivo presentar actividades desarrolladas por proyecto de extensión de la Universidad, que tuvo la intención de promover espacio de escucha, conversación y reflexión sobre los vínculos afectivos con personas detenidas en unidades semiabertas de la Secretaría de administración penitenciaria del estado de Rio de Janeiro (SEAP). Se divulga y discute aquí los resultados obtenidos en cinco reuniones realizadas en cuatro unidades de régimen semi abierto, donde los grupos se realizaron con los detenidos. Se observó la importancia de desarrollar actividades que permiten trabajar la transición de lo momento vivido dentro de la prisión para lo contexto extramuros, colaborando con la reflexión sobre los proyectos de vida en libertad.

Palavras clave: Sistema Penitenciário. Régimen Semi-aberto. Extensión Universitaria. 


\section{INTRODUÇÃO}

O Projeto Vida, desenvolvido pela Secretaria de Administração Penitenciária do Estado do Rio de Janeiro (SEAP), tem como objetivo a promoção de saúde e de cidadania daqueles que estão cumprindo pena de prisão estabelecida por sentença judicial, bem como de seus familiares. No decorrer de suas atividades, o projeto considerou relevante ampliar as ações já desenvolvidas, propondo parcerias com universidades. Em 2013, o Programa de Formação em Direitos da Infância e da Juventude - Pró-Adolescente recebeu convite para desenvolver atividades junto a algumas unidades prisionais de regime semiaberto do estado do Rio de Janeiro. As reuniões iniciais entre as duas equipes resultaram no projeto AproximAção, que teve por objetivo promover espaço de escuta, conversação e reflexão sobre vínculos afetivos com pessoas que estavam cumprindo pena em unidades prisionais de regime semiaberto da SEAP.

O título do projeto elaborado expressa a finalidade de propor uma aproximação e uma ação junto aos detentos. Este trabalho de extensão universitária fundamenta-se também na importância de aproximar a universidade do sistema prisional, propiciando tanto a construção como a difusão de conhecimentos que possam colaborar com ações de promoção de saúde, cidadania, garantia de direitos, fortalecimento de vínculos sociais, atenção aos egressos, dentre outras. Encontram-se também dentre seus objetivos fornecer subsídios para possíveis restabelecimentos de contatos extramuros, contribuir com experiências de trabalho nesse campo, além de produzir informações que ajudem a refletir sobre a prática de psicólogos no sistema prisional.

\section{UM OLHAR SOBRE O INTERIOR DAS PRISÕES}

Segundo informações da Agência Senado (VIEIRA, 2015) o Brasil é o quarto país com maior número de presos. Enquanto Estados Unidos, China e Rússia, países que reúnem maior quantitativo, vêm reduzindo esse contingente nos últimos anos, no Brasil, inversamente, houve vertiginoso crescimento. Em 2016, o Ministério da Justiça e Segurança Pública informa que (BRASIL, 2016) de acordo com o Levantamento Nacional de Informações Penitenciárias (Infopen) de 2014, “a população penitenciária brasileira chegou a 622.202 presos em dezembro de 2014". No que diz respeito à denominada taxa de encarceramento, que se refere ao número de pessoas presas por grupo de 100 mil habitantes, o Brasil encontra-se na sexta posição mundial. $\mathrm{Na}$ mesma data Rodrigues (2016), em referência ao citado levantamento, esclarece que "no Brasil 
são 306 presos para cada 100 mil habitantes. A média mundial é de 144 presos por 100 mil pessoas". Sendo que desde o ano 2000 o aumento desta população no Brasil foi de $167 \%$.

No que diz respeito às prisões brasileiras verifica-se que as propostas de ressocialização, reintegração e reeducação - previstas na Lei de Execução Penal (BRASIL, 1984), dentre outros documentos - se perdem em meio à lógica punitiva e às condições degradantes e humilhantes as quais as pessoas que cumprem pena no cárcere estão assujeitadas. Como mostra o relatório final da Comissão Parlamentar de Inquérito (CPI) do Sistema Carcerário de 2008 (BRASIL, 2009) “a CPI encontrou homens amontoados como lixo humano em celas cheias, se revezando para dormir, ou dormindo em cima do vaso sanitário" (p. 247), além disso, "mais de $80 \%$ da população carcerária está ociosa, sem qualquer tipo de atividade educativa” (p. 250).

Apesar dos graves problemas do sistema penal do país, algumas iniciativas despontam visando articular redes, fortalecer laços sociais e reafirmar a condição humana de sujeitos em cumprimento de pena de prisão. Santos, Néri, Oliveira, Quitete e Sabroza (2009) organizaram um grupo de trabalho em unidades prisionais femininas do estado do Rio de Janeiro, denominado "Feminino e Criminalidade", onde passaram a pesquisar e discutir a criminalidade feminina e propor alternativas de intervenção. Os autores criaram, também, grupos de promoção de diálogos que resultaram em frutos positivos dentro dessas instituições. Já o projeto "Leitura também é saúde" (BANDEIRA, 2012), promoveu a construção de uma biblioteca e a realização de oficinas de leitura no sistema prisional no estado do Rio de Janeiro usando a leitura como instrumento de resistência frente às adversidades da prisão.

\section{PROJETO APROXIMAÇÃO}

A proposta inicial de trabalho do AproximAção foi a de promover encontros com grupos de detentos, com duração de duas horas cada, em cinco unidades prisionais de regime semiaberto do estado do Rio de Janeiro contempladas pelo Projeto Vida. A possibilidade de retorno estava prevista, entretanto, a atividade foi cancelada em uma das instituições e somente em uma unidade houve uma segunda reunião. Desse modo, foram realizados cinco encontros em quatro unidades prisionais nos meses de junho, agosto, setembro e outubro de 2013.

A equipe do AproximAção - composta por docente do Instituto de Psicologia, bolsistas de iniciação científica, bolsistas de extensão, psicólogos associados ao Programa, além de alunos de mestrado e de doutorado - direcionava cinco de seus integrantes a cada atividade. Em todas as unidades prisionais visitadas a equipe passou por revista antes de ser encaminhada para o local da 
atividade. Vale destacar que cada encontro contou com a participação de 20 a 30 internos. A seleção dos detentos que iriam participar do grupo ficou a cargo da instituição.

A primeira etapa do trabalho consistia na apresentação do projeto e dos participantes. A medida em que os internos chegavam para a atividade e ingressavam na sala perguntava-se seus nomes e como gostariam de ser chamados. Em seguida, os nomes ou apelidos eram escritos em etiquetas que podiam ser coladas nas roupas. Tal preocupação visava não desprezar possíveis identidades construídas ao longo da vida, em que um apelido pode dizer muito mais de si do que o nome dado no nascimento. Cabe ressaltar que no início do encontro os membros da equipe já estavam com seus nomes destacados. O momento inicial servia não só para as apresentações como também para circunscrever os limites e as possibilidades da atividade que seria empreendida, com o intuito de criar uma espécie de contrato de trabalho entre equipe e detentos. Procurava-se também deixar claro que a equipe possuía uma parceria com o Projeto Vida, já conhecido pelos internos. Mesmo assim, algumas vezes houve questionamento se a participação no projeto traria algum benefício para a pena.

Posteriormente era solicitado aos detentos que se dividissem em grupos de quatro ou cinco integrantes. Com os grupos já formados, era apresentado o objetivo da atividade que consistia na confecção de um painel sobre as experiências de vida dentro da unidade e as expectativas fora. Para tanto, cada grupo recebia um painel de cartolina já pronto, as quais foram divididas ao meio. Do lado esquerdo, no alto da folha, estava escrito a palavra dentro e do lado direito o termo fora. A atividade consistia em preencher os espaços dentro e fora com foco nas seguintes questões: “Quando você está aqui dentro, o que permanece lá fora?” "Quando sair, tem algo daqui de dentro que você levará?" "O que foi construído dentro do sistema prisional que ajudará em relação às expectativas para o momento no qual estarão fora?” Nesses painéis era possível escrever, desenhar e colar o que desejassem. Para isso, a equipe distribuía: cola em bastão, revistas, resmas de papel branco e colorido, canetinhas, lápis de cor, durex. O inventário do material foi previamente descrito à direção de cada unidade e conferido sistematicamente antes e depois de cada atividade.

O tempo de confecção do painel era de 20 minutos. Excedido este prazo cada grupo escolhia um representante para expor, de forma sucinta, em aproximadamente cinco minutos, o material elaborado. Após essa apresentação, a equipe fazia o resgate dos temas contemplados motivando uma discussão a partir do que foi identificado como semelhante e do que era distinto nos trabalhos produzidos. Nesse momento, havia o incentivo para que todos pudessem expor suas opiniões e para que coletivamente fizessem uma reflexão sobre os assuntos abordados nos painéis. Esta etapa foi programada para trinta minutos. Por fim, todos os participantes, inclusive 
os membros da equipe, eram convidados a dizer uma palavra que expressasse como cada um estava se sentido após a atividade.

\section{ANÁLISE DA EXPERIÊNCIA}

A seguir serão reproduzidas as principais palavras e frases contidas nos cartazes confeccionados. No espaço destinado às expectativas de vida dentro da unidade as seguintes expressões foram frequentes: "Deus como força", "futuro duvidoso", "abandono", "sofrimento", “saudades", “tristeza", “dor", “inferno". Além dessas, destacaram-se: "ser mercadoria para o governo", "sem expectativa de vida melhor", "sem ocupação", "vida arruinada", "falta de saúde e tratamento digno", "insalubridade total", "perdas", "ser contado todo dia", "justiça cega e distante”, "gostava de coisas fáceis”, “difícil confiar no governo”. No que concerne às expectativas relativas à vida fora do sistema prisional, os participantes das atividades frisaram principalmente: "liberdade", "trabalhar", "vida digna", "futuro", "família", "escola/curso", “oportunidade de mudar a vida", "natureza”, “saúde”, "amor", “esperança”,"paz”, "nova vida", "arrependimento", “construir/ reconstruir família”, "igualdade social”, "fim da escuridão", "aprender coisas boas”, “ o pior já passou?”, "um Brasil sem discriminação", "vida sem álcool e drogas".

Foi observada grande discrepância entre as palavras e expressões que representavam o dentro e o fora do sistema prisional. Muitos conteúdos e ideias se apresentaram de maneira polarizada, dicotômica, sendo direcionados de forma predominantemente negativa ao lado de dentro e majoritariamente positiva ao lado de fora. O momento de discussão em grupo serviu como oportunidade de expressão de sentimentos, emoções, angústias e desejos, bem como de avaliação das condições de vida dos detentos dentro do sistema prisional.

A conjuntura insalubre da prisão também foi citada como perigosa não só para os próprios internos, como para seus familiares em dias de visita. Foi exposto o caso de um dos internos cuja esposa faleceu após ter contraído tuberculose ao lhe fazer visitas. A tuberculose é uma doença endêmica no sistema prisional brasileiro que leva a morte não só de presos, como de seus familiares. A precariedade do atendimento médico dentro da prisão também foi salientada.

A questão do tempo foi tema comum em diversos encontros evidenciando a ausência de ocupação dentro das prisões. Houve menção a um tempo ocioso, de muita ansiedade, com expectativa de que o regime semiaberto fosse melhor do que o fechado. Entretanto, para eles, a realidade era a mesma nos dois regimes. Em uma unidade feminina as internas afirmaram que o regime semiaberto era pior do que o fechado, pois existiam pouquíssimas possibilidades de 
cursos profissionalizantes e de trabalho. Notou-se um desejo coletivo nesse grupo de mulheres de que a lei se concretizasse por meio do respeito e concessão de seus direitos.

Preocupações concernentes à ausência de recursos materiais em suas casas e à carência de itens de subsistência básica para suas famílias promoviam reflexões sobre o que fazer fora da prisão para evitar o retorno ao crime. A dificuldade em arranjar emprego após o encarceramento devido ao estigma de ter sido presidiário facilitava, segundo a fala dos internos, a reinserção no mundo do crime que era visto como única oportunidade. Ao lado desse desejo estava a incerteza do que iria acontecer no dia em que deixassem a prisão. $O$ futuro incerto e duvidoso era o disparador de angústia, medo, dor e insegurança.

A palavra inferno foi utilizada repetidamente para fazer referência à vida no sistema prisional, contudo, durante a atividade foi apontado que também aprenderam a ter humildade, disciplina e respeito coletivo. Numa unidade os internos fizeram questão de deixar claro que toda consciência que desenvolveram não foi consequência do sistema prisional e da dureza da prisão, que para eles não trouxe bônus, mas de ensinamentos provenientes do grupo que formaram. Foi destacada a ausência de oportunidades de trabalho fora da instituição e, em alguns casos, a ausência de ocupação dentro das unidades. A importância dos vínculos entre eles, a amizade, o valor do coletivo e a relação com a família foram enfatizados de forma positiva em quase todos os encontros. Reclamações sobre a ausência do Estado, falta de direitos e de emprego também se fizeram presentes tanto nos cartazes produzidos, quanto nos debates.

A religião era uma das poucas oportunidades de atividade, sendo valorizada. A igreja evangélica estava presente em quase todas as unidades onde foram realizados os encontros. A menção a Deus era habitual nos relatos dos presos, seja para justificar de onde provinha a força para suportar as dificuldades do cárcere, seja como base da esperança de um futuro melhor.

O ingresso na prisão como um passe de mágica era frequente no discurso dos detentos. Observou-se que evitavam falar sobre seus crimes. As expectativas em relação ao mundo que encontrariam fora da prisão eram muitas e incluíam o trabalho, a família e a ideia de uma vida nova onde teriam amor, alegria, carinho, amizade, dignidade, esperança, paz e sonhos realizados. Tais desejos eram expressos por meio de figuras como paisagens, carros, casas que só seriam possíveis quando conseguissem a tão citada e sonhada liberdade. A esperança de mudar de vida, de passear com a família, de ser um cidadão honesto apareceu nos cartazes produzidos. Contudo, foi possível notar também falas que expressavam o receio de encontrar dificuldades para conseguir trabalho, obter benefícios, retomar o contato com a família e conseguir uma reaproximação com os filhos. Esse entendimento sugeria que estavam cientes do ato cometido e que gostariam de possuir condições para mudar e recomeçar suas vidas. 
A ausência de políticas públicas também foi uma questão discutida. Os presos se queixaram da falta de escolas, de saneamento básico e de oportunidades. Um interno relatou sentir-se sequestrado, pois estava preso há quatro anos e oito meses e, até então, não mantinha contato com nenhum membro de sua família. Outro detendo afirmou ser natural da Bahia, necessitando ser transferido para seu estado e questionou como seria possível falar em ressocialização sem contato com a família. O sentimento de abandono estava relacionado não só ao isolamento próprio da prisão, bem como à ausência de profissionais que pudessem lhes atender.

Apesar de um dos internos ter afirmado que nas prisões havia o encarceramento do corpo, mas não o encarceramento da mente, notou-se certa dificuldade de simbolização e a permanência no concreto como modo de compreensão do mundo pela maioria dos internos.

A diferença entre a escuridão dentro da prisão e o fim da escuridão fora dela, evidenciado pelos participantes da atividade do projeto AproximAção, salienta a necessidade de se desenvolver atividades com foco na transição dentro/fora do regime prisional com o intuito de fazer dele um tempo e um espaço para a construção de projetos de vida que evitem a reincidência do crime e o retorno ao sistema prisional.

\section{CONSIDERAÇÕES FINAIS}

A finalidade da proposta inicial de analisar os espaços dentro e fora do sistema prisional teve como foco a transição que deve ocorrer no regime semiaberto, quando se inicia a construção de novos projetos de vida. Notou-se uma grande idealização da vida fora da prisão que seria vista ao mesmo tempo como o oposto e a solução dos problemas do cárcere. A disparidade entre o que obteriam com o ingresso no regime semiaberto e a realidade que vivenciavam também foi ressaltada, na medida em que os internos acreditavam que a progressão de regime lhes proporcionaria a inserção em cursos profissionalizantes e até mesmo no mercado de trabalho externo, o que não ocorria.

Especificamente no que concerne às demandas de ordem psicológica, percebeu-se a deficiência de espaços nos quais a fala e expressão dos detentos possam ser valorizadas, sendo esse um dos principais temas enfatizados. Observou-se, assim, que o projeto AproximAção pode ser um veículo para o desenvolvimento de trabalhos que abarquem o coletivo institucional, em particular no sistema prisional, promovendo espaços de diálogo e reflexão, sendo possível e necessário desenvolver propostas de intervenção a longo prazo neste contexto social.

\section{AGRADECIMENTOS}


Aproximação: dialogando sobre contatos extramuros

À Camilla Felix Barbosa de Oliveira, à Joyce Barros Pereira, à Rafael Ribeiro de Souza Maia, à Thaís Vargas Menezes, à Deborah Thiers de Carvalho e à Alan Lima Alves pela participação no projeto AproximAção.

\section{REFERÊNCIAS}

BANDEIRA, M, B. Sistema Prisional. Contando e Recontando Histórias. As oficinas de leitura como processos inventivos de intervenção. Curitiba, Juruá Editora, 2012. 160p.

BRASIL. Lei de Execução Penal. Lei no 7.210, de 11 de julho de 1984.

BRASIL Congresso Nacional. Câmara dos Deputados. Comissão Parlamentar de Inquérito do Sistema Carcerário. CPI sistema carcerário. - Brasília : Câmara dos Deputados, Edições Câmara, 2009. 620 p. Disponível em < http://bd.camara.leg.br/bd/handle/bdcamara/2701 >. Acesso em: 10. jan. 2016.

BRASIL Ministério da Justiça e Segurança Pública. Notícias. População carcerária brasileira chega a mais de $\mathbf{6 2 2}$ mil detentos. Brasília, 26 de abril de 2016. Disponível em < http://www.justica.gov.br/noticias/populacao-carceraria-brasileira-chega-a-mais-de-622-mildetentos >. Acesso em: 16. jun.2016.

RODRIGUES, F. Número de presos no Brasil mais que dobra em 14 anos. UOL Notícias Política. Blog do Fernando Rodrigues, 26 de abril de 2016. Disponível em < http://fernandorodrigues.blogosfera.uol.com.br/2016/04/26/numero-de-presos-no-brasil-maisque-dobra-em-14-anos $>$. Acesso em: 16. jun.2016.

SANTOS, M. B. S. DOS; NÉRI, H. F; OLIVEIRA, M. F. L.; QUITETE, B; SABROZA, A. Do outro Lado dos Muros: a Criminalidade Feminina. Mnemosine Vol.5, n², p. 174-188, 2009.

VIEIRA, A. Brasil caminha para ser país com maior número de presos, alerta Diretora do Depen. In: Agência 2015.2 Denado. Disponível em: < http://www12.senado.leg.br/noticias/materias/2015/09/17/brasil-caminha-para-ser-paiscom-maior-numero-de-presos-alerta-diretora-do-depen

>. Acesso em: 10. jan. 2016. 